\title{
PARÂMETROS CINÉTICOS DA GLUTATIONA S-TRANSFERASE E SUA ATIVAÇÃO POR EXTRATOS DE VEGETAIS ${ }^{1}$
}

\author{
Maria Célia Lopes TORRES ${ }^{2, *}$ Nilda de Fátima Ferreira SOARES ${ }^{3}$, June Ferreira MAIA ${ }^{3}$
}

\begin{abstract}
RESUMO
Este estudo teve como objetivos avaliar a indução da Glutationa S-Transferase, com extratos de vegetais, e caracterizar os parâmetros cinéticos desta enzima. Foram obtidos os extratos aquoso, etanólico e hexanólico de vegetais, amplamente consumidos no Brasil, como berinjela (Solanum melongena L.), couve-flor (Brassica oleracea L.), couve (Brassica oleracea L.), brócolis (Brassica oleracea L.), couve-debruxelas (Brassica oleraea L.), cebola (Allium cepa L.), alho (Allium sativumL.); vegetais que apresentam gosto amargo, como jiló (Solanum gilo Raddi), guariroba (Syagrus oleracea Becc.), mostarda (Brassica nigra L.), carqueja (Cacalia spp.), e de plantas relacionadas, na cultura popular, como curadoras de determinadas doenças, como a babosa (Aloe vera L.). A atividade da enzima foi determinada usando como substrato o 1 cloro 2,4 dinitrobenzeno, na presença dos extratos vegetais. A mistura da reação, sem a presença do extrato, foi considerada controle. Das amostras de vegetais avaliadas, a berinjela, a couve e o brócolis apresentaram maior indução na atividade da GST, sendo o extrato etanólico o mais eficaz. A enzima apresentou um $\mathrm{V}_{\max }$ de 0,016 abs. min - $^{-1} /$ unidade da enzima e um $\mathrm{K}_{\mathrm{m}}$ de $0,323 \mathrm{mM}$. O baixo valor de $\mathrm{K}_{\mathrm{m}}$ encontrado indica uma alta especificidade da enzima pelo substrato 1 cloro 2 , 4 dinitrobenzeno e a atividade máxima da enzima foi na faixa de $\mathrm{pH}$ entre 6,5 e 7,0.

Palavras-chave: Glutationa S-Transferase; atividade enzimática; extratos de vegetais.
\end{abstract}

\section{SUMMARY}

KINETICS PARAMETERS OF GLUTATHIONE S-TRANSFERASE AND ITS ACTIVATION BY VEGETABLE EXTRACTS. This study was done to evaluate induction Glutathione S-Transferase, with vegetable extracts, and characterize its kinetics parameters. The aqueous, alcoholic, and hexanoic extracts were obtained from vegetables widely consumed in Brazil: eggplant (Solanum melongena L.), cauliflower (Brassica oleracea L.), cauli leaves (Brassica oleracea L.), broccoli (Brassica oleracea L.), Brussels sprout (Brassica oleraea L.), onions (Allium cepa L.), garlic (Allium sativum L.); and bitter tasting vegetable such as jiló (Solanum gilo Raddi), guariroba (Syagrus oleracea Becc.), black mustard (Brassica nigra L.), carqueja (Cacalia spp.) and plants popularly considered as medicinal for curing certain diseases such as aloe vera (Aloe vera L.). The enzyme activity was determined using 1 chloro 2, 4 dinitrobenzene (CDNB) as substrate, in the presence of vegetable extracts. The reaction mixture, without the extract served as control. Of the botanical samples evaluated, eggplant, cauli leaves and broccoli showed highest induction of GST activity, the most being the alcoholic extract. The enzyme showed a $\mathrm{V}_{\max }$ of 0.016 abs.min ${ }^{-1}$ unit of enzyme and a $\mathrm{K}_{\mathrm{m}}$ of $0.323 \mathrm{mM}$. Low $\mathrm{K}_{\mathrm{m}}$ value indicates high specificity of the enzyme with CDNB substrate and the maximum enzyme activity was in the $\mathrm{pH}$ range of 6.5 to 7.0 .

Keywords: Glutathione S-Transferase; enzyme activity; vegetable extracts.

\section{1 - INTRODUÇÃO}

As Glutationas S-Transferases (GSTs) (E.C 2.5.1.18) são um grupo de enzimas que apresentam especificidades comuns em relação ao substrato aceptor eletrofílico. Uma característica da GST é a elevada especificidade pela glutationa reduzida (GSH); após combinada, apresenta maior especificidade para um segundo substrato. A GSH, formada pelos aminoácidos glicina, cisteína e glutamato, é o co-fator para a GST. A capacidade redutora da GSH é determinada pelo grupamento $\mathrm{SH}$, presente na cisteína. Considerada a principal enzima detoxificante da fase 1l, desempenha papel fisiológico na iniciação da detoxificação de potenciais agentes alquilantes, incluindo compostos farmacologicamente ativos, gerados intracelularmente ou encontrados na forma de xenobióticos. A reação de conjugação do grupo sulfidrílico da glutationa com grupos eletrofílicos de compostos xenobióticos, catalisada pela GST, torna os

${ }^{1 .}$ Recebido para publicação em 23/08/2002. Aceito para publicação em 30/01/2004 (000963).

2. Universidade Federal de Goiás - Escola de Agronomia e Engenharia de Alimentos - Campus Samambaia, Caixa Postal 131, CEP: 74001-970, Goiânia, GO.

3. Universidade Federal de Viçosa - Departamento de Tecnologia de Alimentos - Campus Universitário, CEP: 36570-000, Viçosa, MG.

* A quem a correspondência deve ser enviada. produtos da reação menos tóxicos e mais solúveis em água, facilitando a excreção $[4,5,13,14]$.

Diferentes compostos, incluindo xenobióticos tóxicos e produtos reativos de processos intracelulares, como peroxidação de lipídios, atuam como substratos para a GST. Os substratos eletrofílicos normalmente compartilham característica de moléculas hidrofóbicas e estruturalmente são bastante diversos [12].

A importância dessa família de proteínas se deve a sua elevada concentração, principalmente no fígado de mamíferos. As GSTs mais estudadas, com respeito a estrutura e mecanismos, são aquelas isoladas de fígado de ratos [1].

Extratos de vegetais e o vegetal desidratado em pó têm sido relacionados como ativadores da GST. Em estudos in vitro, quando incubados em células de mamíferos, os extratos de vegetais têm-se mostrado eficazes na indução da GST. Em experimentos com animais de laboratório, especialmente ratos ou camundongos, alimentados com dietas adicionadas do extrato ou do vegetal desidratado em pó, a atividade da GST tem sido elevada em diferentes tecidos, como fígado, intestino, pulmão, entre outros. Diversos pesquisadores relatam que a ativação da GST, em tecidos de animais, tem sido associada como fator de prevenção do câncer $[2,4,5,13]$. 
SIPES \& GANDOLFI [11] consideram uma substância ativadora aquela que pode combinar com a enzima para alterar sua atividade catalítica. Segundo WHITAKER [15], a ligação de uma molécula de substrato, no centro ativo da enzima, resulta na formação de um produto, mas a ligação de uma segunda molécula de substrato, em outro local, não resulta na conversão deste substrato em produto, porém eleva a taxa de conversão do primeiro substrato ligado ao sítio ativo para produto. Esse aumento na taxa de conversão é considerado ativação.

A determinação da cinética das enzimas é importante como medida da velocidade da reação e de como esta velocidade é afetada pelas condições químicas e físicas. Estudos cinéticos fornecem informações sobre mecanismos básicos de catálise e outros fatores que caracterizam a enzima [7].

Os objetivos deste estudo foram avaliar a indução da atividade da GST com extratos aquoso, etanólico e hexanólico de vegetais desidratados (couve, jiló, berinjela, brócolis, babosa, mostarda, carqueja, couve-flor, couve-de-bruxelas, alho, cebola, guariroba) e caracterizar os parâmetros cinéticos da enzima GST (SIGMA), purificada de fígado de ratos.

\section{2 - MATERIAL E MÉTODOS}

\section{1 - Materiais}

A enzima Glutationa S-Transferase (GST) purificada de fígado de ratos, a glutationa reduzida (GSH) e o substrato 1 cloro 2-4 dinitro benzeno (CDNB) foram obtidos da SIGMA.

Os vegetais berinjela (Solanum melongena L.), couve-flor (Brassica oleracea L.), couve (Brassica oleracea L.), brócolis (Brassica oleracea L.), couve-de-bruxelas (Brassica oleracea L.), cebola (Allium cepa L.), alho (Allium sativum L.), jiló (Solanum gilo Raddi), mostarda (Brassica nigra L.), carqueja (Cacalia spp.) e babosa (Aloe vera L.) foram obtidos no mercado varejista da cidade de Viçosa e em regiões próximas. O palmito guariroba (Syagrus oleracea Becc.) foi obtido no mercado varejista da cidade de Goiânia-GO.

\section{2 - Métodos}

\subsection{1 - Preparo da solução da enzima}

Foram dissolvidos $10 \mathrm{mg}$ da enzima em pó em solução-tampão de fosfato de sódio $0,1 \mathrm{M}$ pH 6,5, contendo $1 \mathrm{mM}$ de EDTA, e o volume foi completado para $25 \mathrm{~mL}$.

Conforme informações contidas no frasco de acondicionamento da enzima, uma unidade conjugará 1,0mM de CDNB com GSH reduzida, por minuto, em pH 6,5, a $25^{\circ} \mathrm{C}$. Cada mg do sólido continha 19 unidades.

\subsection{2 - Determinação da concentração de enzi- ma na reação}

Para determinar a concentração da enzima com atividade nas condições do experimento, alíquotas de 30 ,
$50,80,100,120$ e $140 \mu \mathrm{L}$ de solução da enzima foram tomadas. A atividade foi determinada conforme metodologia descrita por HABIG et al. [1]. O ensaio foi conduzido em triplicata, a $25^{\circ} \mathrm{C}$, com tampão fosfato de potássio $0,1 \mathrm{M}$ e pH 6,5 , na presença de $1 \mathrm{mM}$ de glutationa reduzida, $1 \mathrm{mM}$ de CDNB (preparado em $80 \%$ de etanol), e alíquotas da solução da enzima. Ensaio da mistura, sem adição da enzima, foi usado para verificar a taxa de reações não-enzimáticas. A correção nas medidas de absorbância da reação enzimática foi realizada pela subtração da absorbância na ausência da enzima. A taxa da reação, para cada concentração da enzima, foi monitorada a $340 \mathrm{~nm}$, usando um espectrofotômetro modelo GBC-UV 918, realizando-se leituras de 10 em 10 segundos, durante três minutos. Os dados foram representados em gráfico de Abs (nm) versus tempo (seg) e foi calculada a taxa da reação (Abs. $\mathrm{min}^{-1}$ ) para as diferentes concentrações da enzima, por meio da equação de regressão linear.

\subsection{3 - Caracterização da enzima}

Para a caracterização da enzima, foram determinadas a taxa da reação em diferentes concentrações de substrato $(\mathrm{CDNB})$, a velocidade máxima $\left(\mathrm{V}_{\max }\right)$ de reação da enzima e a constante de Michaelis-Menten $\left(\mathrm{K}_{\mathrm{m}}\right)$ para o substrato CDNB.

\section{- Determinação da taxa de reação (Vo)}

Os parâmetros cinéticos das catálises enzimáticas têm sido determinados tradicionalmente pelo uso da velocidade inicial $\left(\mathrm{V}_{0}\right)$, quando diferentes concentrações de um substrato são usadas. A determinação dos valores de $\mathrm{V}_{\max }$ e $\mathrm{K}_{\mathrm{m}}$ é importante numa reação enzimática. $\mathrm{O}$ valor de $\mathrm{K}_{\mathrm{m}}$ indica a afinidade da enzima pelo substrato. Quanto menor o $\mathrm{K}_{\mathrm{m}}$, maior a afinidade da enzima pelo substrato; logo, a velocidade da reação também será maior. $\mathrm{O}$ valor de $\mathrm{V}_{\max }$ indica que todo o substrato está sendo utilizado pela enzima.

A taxa da reação foi determinada mantendo-se fixa a concentração da GSH em $1 \mathrm{mM}$ e variando a concentração do CDNB, em tampão fosfato $0,1 \mathrm{M}, \mathrm{pH} 6,5$, a $25^{\circ} \mathrm{C}$. A atividade da GST foi monitorada nas concentrações de $0 ; 0,25 ; 0,50 ; 0,75 ; 1,00 ; 1,25 ; 1,50 ; 1,75$; e 2,00mM de CDNB. Os dados obtidos da leitura da absorbância a 340nm, pelo tempo de um minuto, para cada concentração, foram representados graficamente e calculada a velocidade da reação $\left(V_{0}\right)$ pela equação de regressão linear $(\mathrm{y}=\mathrm{ax}+\mathrm{b})$, sendo $\mathrm{a}=\mathrm{V}_{0}$. Assim, foi possivel determinar o efeito desse substrato na velocidade inicial da reação, podendo-se, então, calcular a velocidade máxima $\left(\mathrm{V}_{\max }\right)$ da reação e obter a constante de Michaelis-Menten $\left(\mathrm{K}_{\mathrm{m}}\right)$ para o CDNB [10,15].

- Determinação da $\mathrm{V}_{\max }$ e $\mathrm{K}_{\mathrm{m}}$

Segundo NAQUI \& CHANCE [8], a cinética da maioria das reações catalisadas por enzimas obedece à equação de Michaelis-Menten.

A partir dos valores de velocidade da reação $\left(\mathrm{V}_{0}\right)$ e da concentração do substrato CDNB [S], os coeficien- 
tes cinéticos, a velocidade máxima $\left(\mathrm{V}_{\max }\right)$ e a constante $\left(\mathrm{K}_{\mathrm{m}}\right)$ de Michaelis-Menten foram calculados, utilizando o método Lineweaver-Burk. A equação da reta $\mathrm{Y}=\mathrm{ax}+\mathrm{b}$ foi determinada, sendo $\mathrm{y}=1 / \mathrm{vo} ; \mathrm{x}=1 / \mathrm{S}$; a declividade (a) $=\mathrm{K}_{\mathrm{m}} / \mathrm{V}_{\max }$; e o intercepto $\mathrm{b}=1 / \mathrm{V}_{\max }$.

em que

$$
\begin{aligned}
& \mathrm{V}_{\max }=\text { velocidade máxima; } \\
& \mathrm{K}_{\mathrm{m}}=\text { constante de Michaelis-Menten; } \\
& \mathrm{Vo}=\text { velocidade inicial; e } \\
& \mathrm{S}=\text { concentração de substrato. }
\end{aligned}
$$

\subsection{4 - Efeito do pH na taxa de reação}

Para avaliar o efeito do $\mathrm{pH}$ na taxa de reação da GST, foram preparadas diferentes soluções de tampão de fosfato de potássio, com $\mathrm{pH}$ variando de 5,0; 5,5; 6,$0 ; 6,5$; e 7,0 . A atividade da enzima na solução foi determinada de acordo com HABIG et al. [1]. Os dados foram representados em gráfico de Abs. min ${ }^{-1}$ versus variação de $\mathrm{pH}$.

\subsection{5 - Desidratação dos vegetais}

Os vegetais, com exceção do palmito guariroba, foram lavados em água corrente, para retirada de sujidade. O palmito guariroba, obtido na forma congelada, foi descongelado sob refrigeração. Os vegetais foram deixados em local seco, à temperatura ambiente, por aproximadamente oito horas, para secagem superficial. Em seguida, foram fatiados em triturador SIEMENS, pesados e levados ao secador de bandejas, com ventilação forçada $(1,5 \mathrm{~m} / \mathrm{s})$ à temperatura de $45+2^{\circ} \mathrm{C}$, por 24 a 36 horas, dependendo do vegetal, até umidade final de cerca de $12 \%$ em b.u. Após a desidratação, foram moídos em moinho de facas, acondicionados em papel laminado e estocados a $-18^{\circ} \mathrm{C}$ até o uso. A umidade final dos vegetais foi determinada, conforme metodologia descrita pelo INSTITUTO ADOLFO LUTZ [3].

\subsection{6 - Preparo dos extratos}

Os extratos dos vegetais desidratados foram obtidos utilizando a água, o etanol e o hexano como solventes. Para cada parte do vegetal desidratado foram adicionadas 10 partes do solvente, que foram submetidas ao aquecimento por 30 minutos, à temperatura de $100^{\circ} \mathrm{C}$ para a água e de $80^{\circ} \mathrm{C}$ para o etanol e o hexano. $\mathrm{O}$ aquecimento foi realizado em manta aquecedora, acoplada a um sistema de condensação, para evitar perdas dos solventes. O extrato aquoso foi filtrado em papelfiltro Whatman e o volume foi medido. Os solventes dos extratos etanólicos e hexanólicos foram recuperados em rotavapor sob pressão reduzida, obtendo-se os respectivos resíduos isentos dos solventes. Em ambos, foi feito um ajustamento com água contendo 0,1\% de Triton X-100 de um volume fixo. A função do Triton X-100 foi estabilizar a solução, principalmente do extrato hexanólico. A determinação da atividade enzimática, descrita a seguir, foi realizada imediatamente após a preparação dos extratos.

\subsection{7 - Determinação da atividade da Glutationa S-Transferase na presença de extratos de vege- tais}

A atividade da enzima Glutationa S-Transferase (GST) foi determinada de acordo com HABIG et al. [1], usando CDNB como substrato (preparado em $80 \%$ de etanol). O ensaio foi conduzido em triplicata, a $25^{\circ} \mathrm{C}$, com tampão fosfato de potássio $0,1 \mathrm{M}$ e pH 6,5 , na presença de $1 \mathrm{mM}$ de glutationa reduzida, $1 \mathrm{mM}$ de CDNB, $100 \mu \mathrm{L}$ da enzima e 30 a $100 \mu \mathrm{L}$ do extrato de vegetal. Ensaio da mistura, sem adição da enzima, foi usado para verificar a taxa de reações não-enzimáticas. A correção nas medidas de absorbância da reação enzimática com o extrato foi realizada pela subtração da absorbância na ausência da enzima. A mistura da reação sem a presença do extrato foi considerada controle. A mudança direta da absorbância, quando o substrato está conjugado com a glutationa, foi monitorada a 340nm, usando um espectrofotômetro modelo GBC-UV 918.

\subsection{8 - Procedimento}

Em uma cubeta de $3 \mathrm{~mL}$ foi adicionada a mistura da reação, composta do tampão fosfato de potássio $0,1 \mathrm{M}$, pH 6,5 (quantidade suficiente para completar o volume para $3 \mathrm{~mL}$ ), $150 \mu \mathrm{L}$ de GSH (20mM em água deionizada), $150 \mathrm{~mL}$ de CDNB (20mM em água deionizada), 30 a 100 $\mu \mathrm{L}$ do extrato de vegetal e $100 \mu \mathrm{L}$ da solução de enzima. A reação foi iniciada pela adição da solução da enzima e monitorada espectrofotometricamente pelo aumento na absorbância a 340nm, durante três minutos. Os dados foram representados em gráfico de abs (nm) versus tempo (minutos), e a taxa da reação foi determinada pela equação de regressão linear $(\mathrm{y}=\mathrm{ax}+\mathrm{b})$, sendo $\mathrm{a}=$ Vo.

A unidade da atividade da enzima foi definida como a taxa de reação da solução da enzima pura, nas condições do experimento.

\section{3 - RESULTADOS E DISCUSSÃO}

Os resultados da atividade da enzima GST, em diferentes concentrações, estão apresentados na Figura 1. Observa-se que nas concentrações entre 100 e $140 \mu \mathrm{L}$ da solução de enzima ocorreu a linearização com a taxa de reação, ou seja, a partir da concentração de $100 \mu \mathrm{L}$ da solução da enzima a taxa da reação é diretamente proporcional à concentração da enzima. Considerando o alto custo de obtenção da enzima GST, esse resultado foi importante, por indicar qual a menor concentração da enzima que poderia ser usada na reação.

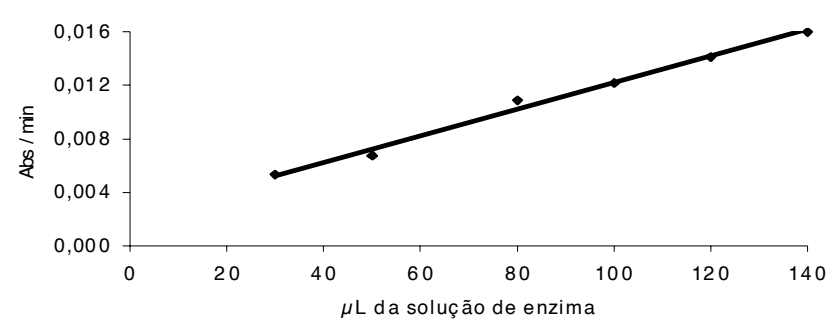

FIGURA 1. Taxa de reação (Abs. $\mathrm{min}^{-1}$ ) das concentrações da solução da Glutationa S-Transferase. 
Os valores obtidos de velocidade $\left(\mathrm{Abs} . \mathrm{min}^{-1}\right)$ da enzima GST, para cada concentração de CDNB usada, estão apresentados na Figura 2. Observa-se que a atividade da GST aumentou linearmente até a concentração de 0,25mM de CDNB, iniciando-se, a partir daí, uma diminuição na taxa da reação até a concentração de $1 \mathrm{mM}$, acima da qual a taxa da reação tende a se estabilizar. Esse resultado foi similar aos estudos realizados por HABIG et al. [1], em que diferentes substratos da GST extraída de fígado de ratos foram avaliados. Para o CDNB esses autores recomendaram a concentração de $1 \mathrm{mM}$ e consideraram que nela o meio está saturado do substrato.

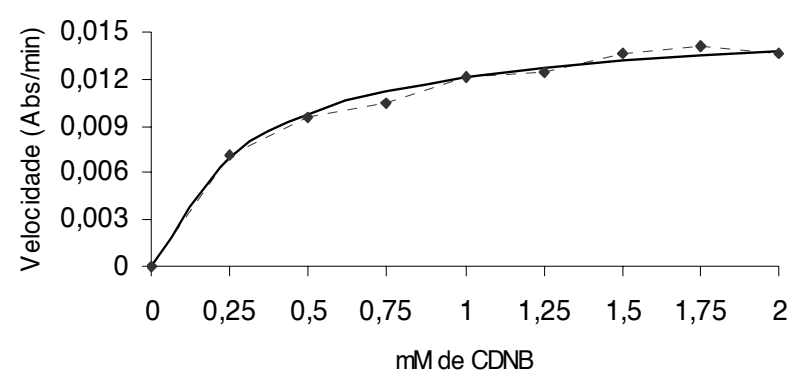

FIGURA 2. Velocidade calculada (---) e velocidade estimada (-) nas diferentes concentrações de CDNB.

Os valores de $\mathrm{K}_{\mathrm{m}}$ e $\mathrm{V}_{\max }$ (Tabela 1) foram calculados pelo método de Lineweaver-Burk, em que foi plotado o gráfico 1 / [S] versus $1 /$ Vo (Figura 3). A equação $\mathrm{Y}=19,8 \mathrm{X}+61,3$ com $u m \mathrm{R}^{2}=0,9974$ foi estimada para os dados coletados:

TABELA 1. Valores calculados de $\mathrm{V}_{\max }$ e $\mathrm{K}_{\mathrm{m}}$ da GST em relação ao substrato CDNB

\begin{tabular}{lc}
\multicolumn{1}{c}{ Parâmetros } & Valores calculados \\
\hline $\mathrm{V}_{\max }\left(\mathrm{mM} \cdot \mathrm{Min}^{-1} / 100 \mu\right.$ L solução da enzima $)$ & 0,016 \\
$\mathrm{~K}_{\mathrm{m}}(\mathrm{mM})$ & 0,323 \\
\hline
\end{tabular}

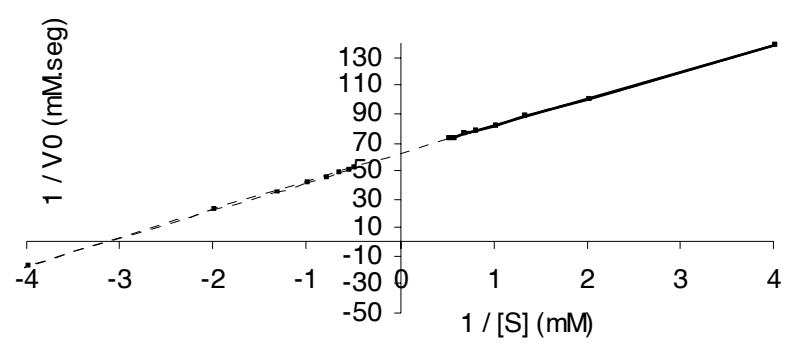

FIGURA 3. Dados de $1 /$ [S] versus $1 /$ Vo conforme método de Lineweaver-Burk (1934).

HABIG et al.[1] determinaram a $\mathrm{V}_{\max }$ e o $\mathrm{K}_{\mathrm{m}}$ das transferases A, B e C, purificadas de fígado de ratos, e encontraram os valores de 300, 860 e 500M.min ${ }^{-1} / \mathrm{mo}^{-}$ les de enzima, respectivamente, para $\mathrm{V}_{\max }$ e 0,06 ; 0,8; e $0,1 \mathrm{mM}$, respectivamente, para $\mathrm{K}_{\mathrm{m}}$ Consideraram o CDNB um bom substrato para as três enzimas, embora tenham constatado diferenças significativas na atividade específica da enzima. YOUNG \& BRIEDIS [17] determinaram o $\mathrm{K}_{\mathrm{m}}$ da GST de cérebro bovino em relação ao CDNB e encontraram um valor de 0,41mM. Observa-se grande variação, tanto de $\mathrm{V}_{\max }$ quanto de $\mathrm{K}_{\mathrm{m}}$, dependendo da enzima purificada.

Na Figura 4 está representada a curva de atividade da reação catalisada pela GST em relação a diferentes valores de $\mathrm{pH}$. Observa-se que a velocidade da GST aumenta na faixa de $\mathrm{pH} 5,0$ a pH 6,5, atingindo a atividade máxima 6,5 a 7,0.

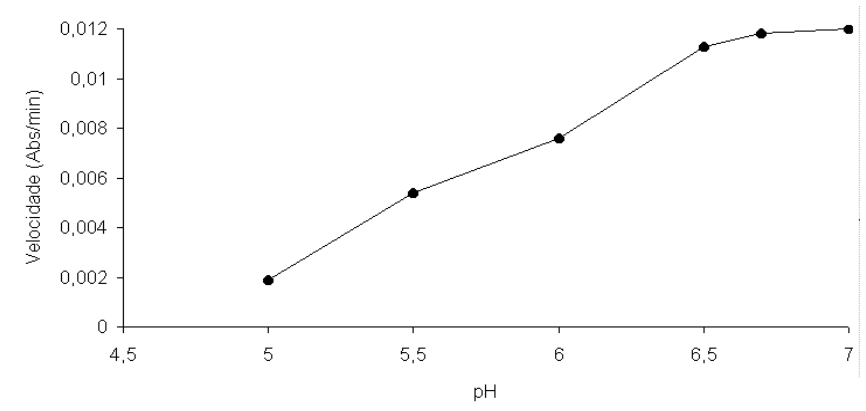

FIGURA 4. Comportamento da Glutationa S-Transferase em diferentes pHs.

Segundo HABIG et al. [1], o pH ótimo a ser usado numa reação enzimática da GST varia de acordo com o substrato. Para o substrato CDNB, esses autores recomendaram o pH de 6,5.

De acordo com NELSON \& COX [9], para a determinação dos parâmetros pH e temperatura, é importante que a concentração de substrato esteja acima da saturação, de modo que a velocidade inicial da reação seja de ordem zero para o substrato. Isso porque, nessa condição, a velocidade inicial de reação é proporcional somente à concentração da enzima. Quando a enzima requer co-fator, este também deve ser adicionado em concentração que exceda seu nível de saturação, de modo que o fator verdadeiramente limitante para a velocidade do sistema seja também a concentração de enzima.

Com o objetivo de verificar se os extratos dos vegetais aumentavam a taxa de reação catalisada pela solução da enzima (GST), foi determinada a taxa de reação da enzima na presença de cada extrato. A taxa de reação da solução da enzima, sem a adição do extrato, foi usada como controle. Os dados foram representados como a razão entre a taxa da reação da enzima, na presença do extrato, e a taxa da reação da solução da enzima, sem o extrato (controle), conforme apresentado na Tabela 2.

A concentração do vegetal usada na reação foi de 100mg. Quando foi comparada a atividade da enzima, para os diferentes meios de extração, observou-se que, na presença dos extratos etanólicos de 7 dos 12 vegetais testados, a GST apresentou a maior taxa de atividade. 
A berinjela, a couve, o brócolis e a guariroba foram os vegetais que apresentaram, no extrato etanólico, os maiores efeitos na indução da atividade da enzima GST.

Alguns vegetais apresentaram inibição da atividade da enzima, dependendo do meio de extração, como, por exemplo, alho (todos os extratos), jiló (extrato hexanólico), cebola (extratos etanólico e hexanólico), guariroba (extratos aquoso e hexanólico) e couve-flor (extrato etanólico). Os extratos de alho e de cebola apresentaram inibição na atividade, porém, quando testados em ratos alimentados com os extratos e com o vegetal desidratado, foram potentes indutores da atividade da GST, além de inibirem o desenvolvimento de tumores [2]. WILLIAMSON et al. [16] também encontraram inibição na atividade da GST de 0,8; 0,9; e 0,8, respectivamente, quando utilizaram os extratos cru e cozido de ervilhas e o extrato autolisado de pimenta vermelha.

Os vegetais que apresentam gosto amargo (jiló, mostarda, carqueja e guariroba) foram testados em razão de determinados constituintes, responsáveis pelo gosto amargo, estarem relacionados com a ativação da enzima, como acontece com o limoneno e limonino, presentes em sucos de frutas cítricas [6]. Neste estudo, dentre esses vegetais, podem-se destacar, como indutores da atividade da enzima GST, o extrato aquoso da carqueja e os extratos etanólicos da mostarda, do jiló e da guariroba.

WILLIAMSON et al. [16] avaliaram extratos de grande variedade de frutas e hortaliças, na indução da atividade da GST. Apesar das metodologias e condições bem diferentes das verificadas neste estudo, esses autores observaram também que a atividade da enzima é afetada pelo tipo de vegetal, pela espécie e pelo tipo de extração. Os extratos de vegetais crucíferos, como couve-de-bruxelas, brócolis, couve-flor e repolho, foram os mais potentes indutores da GST, quando incubados em células HepG2. A relação da atividade da enzima, na presença do extrato e do controle (sem extrato), foi calculada e os autores reportaram que a maior indução foi para os extratos de couve-de-bruxelas, que variou de 1,4 a 1,8 vezes. As variações na indução com os demais extratos foram: brócolis, 1,2 a 1,4 ; couveflor, 1,1 a 1,7; repolho, 1,0 a 1,7; e alface, 1,0 a 1,4 vezes. A maioria dos extratos de frutas, com exceção de "grapefruit" (1,4 vez), teve pouco efeito na indução da atividade da enzima.

Quando se comparam esses resultados com os da Tabela 2, verifica-se que os índices foram similares para couve-flor, inferior para couve-de-bruxelas e superior para brócolis.

Nos dados encontrados por WILLIAMSON et al. [16], a indução entre as mesmas espécies de vegetal geralmente foi maior para os extratos cozidos, obtidos por fervura em água durante 15 minutos, liofilizados e fervidos em metanol $70 \%$ por mais 15 minutos do que para os extratos crus obtidos por fervura em metanol $70 \%$ por 15 minutos. Os autores mencionaram ainda que usaram as células HepG2 por reterem muitas das enzimas envolvidas no metabolismo de xenobióticos, inclusive a GST.

TABELA 2. Taxa da reação da GST em presença de extratos de vegetais

\begin{tabular}{|c|c|c|c|}
\hline Vegetal & Extratos & $\mathrm{Vo} / 100 \mathrm{mg}$ & Razão* \\
\hline & EA & 0,024 & 1,2 \\
\hline \multirow[t]{3}{*}{ Couve-de-bruxelas } & EE & 0,019 & 1,0 \\
\hline & $\mathrm{EH}$ & 0,022 & 1,1 \\
\hline & EA & 0,016 & 0,8 \\
\hline \multirow[t]{3}{*}{ Guariroba } & EE & 0,035 & 1,8 \\
\hline & $\mathrm{EH}$ & 0,014 & 0,7 \\
\hline & EA & 0,021 & 1,1 \\
\hline \multirow[t]{3}{*}{ Jiló } & EE & 0,020 & 1,0 \\
\hline & $\mathrm{EH}$ & 0,015 & 0,8 \\
\hline & EA & 0,048 & 2,4 \\
\hline \multirow[t]{3}{*}{ Cargueja } & EE & 0,023 & 1,2 \\
\hline & $\mathrm{EH}$ & 0,018 & 0,9 \\
\hline & EA & 0,016 & 0,8 \\
\hline \multirow[t]{3}{*}{ Mostarda } & EE & 0,023 & 1,2 \\
\hline & $\mathrm{EH}$ & 0,015 & 0,7 \\
\hline & EA & 0,022 & 1,1 \\
\hline \multirow[t]{3}{*}{ Cebola-branca } & EE & 0,008 & 0,4 \\
\hline & $\mathrm{EH}$ & 0,018 & 0,5 \\
\hline & EA & 0,016 & 0,8 \\
\hline \multirow[t]{3}{*}{ Babosa FL } & EE & 0,025 & 1,3 \\
\hline & $\mathrm{EH}$ & 0,314 & 1,6 \\
\hline & EA & 0,025 & 1,3 \\
\hline \multirow[t]{3}{*}{ Couve } & EE & 0,035 & 1,8 \\
\hline & $\mathrm{EH}$ & 0,023 & 1,2 \\
\hline & EA & 0,024 & 1,2 \\
\hline \multirow[t]{3}{*}{ Brócolis } & EE & 0,046 & 2,3 \\
\hline & $\mathrm{EH}$ & 0,022 & 1,1 \\
\hline & EA & 0,019 & 1,0 \\
\hline \multirow[t]{3}{*}{ Couve-flor } & EE & 0,018 & 0,9 \\
\hline & $\mathrm{EH}$ & 0,021 & 1,6 \\
\hline & EA & 0,014 & 0,7 \\
\hline \multirow[t]{3}{*}{ Alho } & EE & 0,013 & 0,6 \\
\hline & $\mathrm{EH}$ & 0,015 & 0,8 \\
\hline & EA & 0,036 & 1,8 \\
\hline \multirow[t]{2}{*}{ Berinjela } & EE & 0,034 & 1,7 \\
\hline & $\mathrm{EH}$ & 0,024 & 1,2 \\
\hline
\end{tabular}

*Calculado dividindo Vo do extrato pelo Vo da enzima. Vo da enzima foi de 0,020abs/min. EA: extrato aquoso, EE: extrato etanólico, EH: extrato hexanólico

\section{4 - CONCLUSÕES}

A adição do extrato de vegetal diretamente na mistura enzima e substrato mostrou a potencialidade do vegetal em induzir a atividade da GST. No entanto, a biotransformação por sistema enzimático leva à formação de compostos que podem inibir ou ativar a enzima GST. Assim, os testes com animais ou células são recomendados para a indução das reações a que estão submetidos os compostos dos vegetais. 


\section{5 - REFERÊNCIAS BIBLIOGRÁFICAS}

[1] HABIG, W.H.; PABST, M.J.; JAKOBY, W.B. Glutathione $\mathrm{s}$-Transferases. The first enzymatic in mercapturic acid formation. The J. of Biol. Chemistry, v.249, n. 22, p. 7130-7139, 1974.

[2] HUANG, M-T; FERRARO, T.; HO, C-T. Cancer chemoprevention by phytochemicals in fruits and vegetables. tumorigenesis In: HUANG, M-T, OSAWA, T, HO, C-T, RANSEN RT,(Eds). Food Phytochemicals for Cancer Prevention 1 -Fruits and vegetables. Washington, DC: ACS Symposium Series, 1994. p. 2-17.

[3] INSTITUTO ADOLFO LUTZ. 1985. Normas Analíticas. $3^{\text {a }}$. edição. São Paulo.

[4] LAM, L. K. T.; SPARNINS, V.L.; WATTENBERG, L. W. Isolation and identification of kahweol palmitate and cafestol palmitate as active constituents of green coffee beans that enhance glutathione s-transferase activity in the mouse. Cancer Res. v. 42, p. 1193-1198, 1982.

[5] LAM, L. K. T.; ZHANG, J.; ZHANG, F.; ZHANG, B. Inhibition of chemically induced carcinogenesis by 2 n-heptylfuran and 2-n-butylthiophene from roast beef aroma In: Mussinan, C. J.; KEELAN, M. E, (Eds). Sulfur Compounds in Food. Washington, DC: ACS Symposium Series ,1994. p. 278-291.

[6] LAM, L.K.T.; LI, Y.; HASEGAWA, S. Effects of citrus limonoids on glutathione S-transferase activity in mice. J. Agric. Food Chem. , v. 37, p. 878-880, 1989.

[7] LEE, J. M. Biochemical Engineering. New Jersey: Prentice Hall, 1992.

[8] NAQUI, A ; CHANCE, B. A. Semi-intregrated method for the determination of enzyme kinect parameters and graphical representation of the Michaelis-Menten equation. Anal. Bioch., v. 141, p. 179-183, 1984.
[9] NELSON, D. L; COX, M. M. Lehninger: Principles of Biochemistry. $3^{\text {a }}$. edição. New York: Worth Publishers, 2000.

[10] RADIKA, K; NORTHROP, D. A. New kinetic diagnostic for enzymatic mechanisms using alternative substrates. Anal. Bioch. v.141, p.413-417, 1984.

[11] SIPES, G. E GANDOLFI, J. Biotransformation of toxificants In: AMDUR, M. O.;DOULL, J.; KLAASSEN, C. D. (Eds). Cassarett and Doll's Toxicology: The basic science of Poisons. 4a . edição. New york: McGRAW-HILL, INC., 1991. p.88-126.

[12] VAN DER AAR, E. M.; BOUWMAN, T.; COMMANDEUR, N. M.; VERMEULEN, N. P. E. Structure-activity relationships for chemical and glutathione stransferase-catalysed glutathione conjugation reactions of a series of 2-substituded 1-chloro-4-nitrobenzenes. Biochem. J. v. 320, p. 531-540, 1996.

[13] WATTENBERG, L.M. Inhibition of neoplasia by minor dietary constituents. Cancer Res v. 43 (may), p. 2448s2453s (Suppl.), 1983

[14] WHEATley, J. B.; KELley, M. K.; MONTALI, J. A.; BERRY, C. O. A.; SCHMIDT, Jr., D. E. Examination of glutathione S-transferase isoenzyme profiles in human liver using high-performance affinity chromatography. J. Chromat. A v. 663, p. 53-63, 1994.

[15] WHITAKER, Jr. Principles of Enzymology for the Food science, $2^{\text {a }}$. edição. New York: Marcel Dekker, INC, 1994.

[16] WILLIAMSON, G.; DUPONT, M. S.; WANIAGATUNGA, S.; HEANEY, R. K., MUSK, S.R.R.; FENWICK, G.R.; RHODES, M.J.C. Induction of glutathione S-transferase activity in HepG2 cells by extracts from fruits and vegetables. Food Chem. v. 60, n. 2, p. 157-160, 1997.

[17] YOUNG, P. R; BRIEDIS, A. N. Purification and kinetic mechanism of the major glutathione S-transferase from bovine brain. Biochem. J. v. 257, p. 541-548, 1989 